University of Wollongong

Research Online

Faculty of Business - Papers (Archive)

Faculty of Business and Law

2013

A practice-based approach to student reflection in the workplace during a Work-Integrated Learning placement

Christopher Sykes

University of Wollongong, csykes@uow.edu.au

Bonnie Amelia Dean

University of Wollongong, bcord@uow.edu.au

Follow this and additional works at: https://ro.uow.edu.au/buspapers

Part of the Business Commons

Research Online is the open access institutional repository for the University of Wollongong. For further information contact the UOW Library: research-pubs@uow.edu.au 


\title{
A practice-based approach to student reflection in the workplace during a Work- Integrated Learning placement
}

\author{
Abstract \\ In the Work-Integrated Learning (WIL) curriculum, reflection on workplace activities is widely used to \\ support student learning. Recent critiques have demonstrated the limitations of current approaches to \\ support students' reflective learning of workplace practices. By employing a practice-based approach, we \\ seek to refocus WIL reflection on workplace practices, emphasising the 'embedded (social), engaged \\ (practice) and embodied (material) aspects' of students' reflective practices in the workplace. We argue \\ that reflection-in-the-midst-of-action includes an often-overlooked phenomenological contribution that \\ shifts attention from cognition to action. This study uses a case study of one typical WIL student to \\ illustrate the importance of reflection-in-the-midst-of-action and the limitations of pedagogical structure \\ using an e-log and reflective journal to capture reflection-in-the-midst-of-action. We argue that the move to \\ consider reflection as a practice, and the move to refocus reflection to reflection-in-the-midst-of-action, \\ supports a learning approach that is more congruent with workplace action and context.
}

\section{Keywords}

era2015, reflection, workplace, during, practice, work, approach, integrated, learning, placement, student

\section{Disciplines \\ Business}

\section{Publication Details}

Sykes, C. \& Dean, B. A. (2013). A practice-based approach to student reflection in the workplace during a Work-Integrated Learning placement. Studies in Continuing Education, 35 (2), 179-192. 


\section{A practice-based approach to student reflection in the workplace during a Work-Integrated Learning placement}

Christopher Sykes

School of Management and Marketing, Faculty of Commerce, University of Wollongong, Wollongong, Australia

csykes@uow.edu.au

Bonnie Amelia Dean

School of Management and Marketing, Faculty of Commerce, University of Wollongong, Wollongong, Australia

Key words: practice-based approach; reflection; work-intergraded learning, internship, phenomenology

Keywords:

practice-based approach, reflection, work-integrated learning, internship, phenomenology 


\title{
A practice-based approach to student reflection in the workplace
}

\section{during a Work-Integrated Learning placement}

\begin{abstract}
In the Work-Integrated Learning (WIL) curriculum, reflection on workplace activities is widely used to support student learning. Recent critiques have demonstrated the limitations of current approaches to support students' reflective learning of workplace practices. By employing a practice-based approach, we seek to refocus WIL reflection on workplaces practices, emphasising the 'embedded (social), engaged (practice) and embodied (material) aspects' (Yanow and Tsoukas 2009, 1342) of students' reflective practices in the workplace. We argue that reflection-in-the-midst-of-action includes an often-overlooked phenomenological contribution that shifts attention from cognition to action. This study uses a case study of one typical WIL student to illustrate the importance of reflection-in-the-midst-of-action and the limitations of pedagogical structure using an e-log and reflective journal to capture reflection-in-the-midst-ofaction. We argue that the move to consider reflection as a practice, and the move to refocus reflection to reflection-in-the-midst-of-action, supports a learning approach that is more congruent with workplace action and context.
\end{abstract}

Key words: practice-based approach, reflection, work-integrated learning, internship, phenomenology 


\section{Introduction}

Reflection on workplace activities is widely used to support learning in higher education workplace programs. In Australia (the setting for this paper), programs where work-place and classroom learning are linked (Patrick, Peach, Pocknee, Webb, Fletcher and Pretto, 2008) are referred to using the umbrella term Work-Integrated Learning (WIL) (rather than names such as Work-Based Learning, Cooperative Education or practicum used in other countries). For students undertaking WIL, reflecting on workplace experiences encourages re-consideration and potential application of their classroom knowledge in workplace contexts. Such learning through reflection is said to help support students professional development and disciplinary competence, and transition from the classroom to workplace (Patrick et al. 2008; Doel 2009; Howard 2009). In addition, by focusing student attention on contextual and tacit areas of workplace practice, it may also contribute to the development of employability skills (Francis and Cowan 2008; Heel, Sparrow and Ashford 2006). Despite the widespread use of reflection in WIL, and the strong claims for its contribution to students' learning workplace practices, questions remain in the identification of the most beneficial ways for students to do WIL workplace reflection.

While reflection can be understood and practised in multiple ways (most commonly in WIL curricula), reflection is on action, which is an after-the-fact, cognitive process (Heel, Sparrow and Ashford 2006; Knight 1996; Sen 2010). Reflection is also a way of structuring thinking (Hackett 2001) and writing (Ryan 2011a) that leads to the acquisition of higher-order cognitive skills (Francis and Cowan 2008). This emphasis on individual, cognitive processes of recall, description and analysis, is in accord with what Beckett and Hagar (2002) term 'the standard paradigm of learning', in which knowledge is construed as a possession of the individual knower, 
held 'in the mind' in representations detached from the spatial-temporal context of its enactment (Dohn 2011). Building on Beckett and Hagar (2002), recent critiques (Boud 2010; Dohn 2011; Fenwick 2009) demonstrate that such approaches to reflection and learning move the focus of reflection away from the primary actions and practices. While secondary practices have their strengths, they are not useful for assisting students' knowing-in-action.

In contrast to approaches that use reflection-on-action are those that focus on reflective actions as they happen. Schön's $(1983 ; 1987)$ notions of reflection-in-action and professional artistry are usually drawn on to describe the kind of reflective actions that occur in moments of surprise. Scholars have identified several limitations in Schön's $(1983 ;$ 1987) description of reflection-in-action, claiming that reflection remains relatively under-theorised due to the difficulties in conceptualising reflection as inseparable from action (Yanow and Tsoukas 2009, Eraut 1994). Such critiques are particularly salient for examining reflection in WIL, as they refocus attention to learning as knowing-in-action and do not overlook the embodied, enacted practices within the workplace context (Boud, 2010).

By employing a practice-based approach influenced by Heidegger and Wittgenstein, we seek to refocus reflection on workplaces practices, emphasising the 'embedded (social), engaged (practice), and embodied (material) aspects' (Yanow and Tsoukas 2009, 1342) of student reflective practices in the workplace (Boud et al. 1985; Raelin 2007a; 2007b). We argue that what we term 'reflection-in-the-midst-of-action' includes an often-overlooked phenomenological contribution that shifts attention from cognition to action.

This paper examines student reflection in the context of a business WIL work placement, and addresses questions such as: How do student/practitioners reflect on 
practices during their performance? What does reflection-in-the-midst-of-action look like, and how could it be assessed? What sorts of tools are required to structure reflection in the workplace to assist students?

The paper is structured as follows: first, we examine reflection and the popular use of Schön's $(1983 ; 1987)$ reflection-on-action and reflection-in-action for reflection in WIL. Second, in order to examine reflection-in-the-midst-of-action, we develop a practice based approach drawing on Schatzki (1996) and Yanow and Tsoukas (2009), linked to the stages of skill development as developed by Dreyfus and Dreyfus (2005). Third, we present and analyse an illustrative case study using the practice-based approach and the stages of skill development. Finally, we discuss the central aspects of a practice-based approach to reflection-in-the-midst-of-action with suggestions for WIL pedagogy.

\section{What is reflection?}

The concept of reflection as a metaphor for thought processes is usually traced to Dewey (1910), who defines reflection as 'active persistent and careful consideration of any belief or supposed form of knowledge in the light of the grounds that support it and the further conclusion to which it tends' (Dewey 1910, 6). Dewey suggests that a state of perplexity, uncertainty or doubt also precipitates reflection (Boud 1999). Boud (1999) adapts Dewey's definition to include experience — and not just thought — as comprising the reflective domain. Boud states that reflection is 'about learners processing their experience in different ways... exploring their understanding of what they are doing and why they are doing it and impact on others' (Boud 1999, 123). In

recent work, Ryan (2011a) goes further, following Eraut (1994), by suggesting that 
reflection includes making sense of experience as well as re-imagining future experience.

Types and levels of reflection are many and varied (Bain et al. 2002; Kember et al. 1999; Ryan 2011a). Schön's distinction between reflection-on-action and reflectionin-action has interested many scholars in the area of professional education and work (Ryan 2011b). The following sections examine the utility of this distinction for WIL, tracing commonly used approaches identified as reflection-on-action before moving to examine reflection-in-action.

\section{Reflection-on-action}

Reflection-on-action is generally undertaken using cognitive or socio-cognitive forms of learning. In well-known examples, Kember et al. (1999) draw on Mezirow (1991) to discuss reflective and non-reflective thinking and suggest that non-reflective thinking has three expressions: habitual action, thoughtful action and introspection. Furthermore, they divide reflection into content, process and premise reflection (Kember et al. 1999). Bain et al. (2002) developed a five-component scale, 'the 5Rs': reporting, responding, relating, reasoning and reconstructing, to assist assessment of student-teachers' journals. In his psychological approach, Grossman (2009) also privileges cognition, claiming that at least four different levels of reflection exist along a depth continuum: content-based, meta-cognitive, 'self-authorship' and transformative or intensive reflection (Grossman 2009 , 15). Each of the above approaches emphasises the centrality of cognition and its representation in ways expedient for assessment purposes in forms such as journals, $\operatorname{logs}$, blogs and structured questions (for recent examples, see Doel 2009; Freeman and Le Rossignol 2010; Gibson et al. 2011; Dyment, O’Connell and Boyle 2011). 
Ryan's (2011a; 2011b) recent socio-cognitive work similarly attends to the importance of the representation of reflection. In two recent papers focused on academic writing of reflection (Ryan 2011a; 2011b) she employs genre analysis to demonstrate that reflective writing in journals requires the use of carefully structured probing questions to support richer articulation of student experience and events. She attends to the written representation of reflection by supporting students to develop multiple, linguistic and textual devices that enable representation of the multiple domains of reflective practice. Drawing on Langer's (1953) work on performativity, she strongly emphasises the importance of expressive form, as well as content, when representing reflection (Ryan 2011a). She also expands the possible modes of representation to include both the discursive and performative, by advocating representative and performative modes such as role-plays, mime, dance or acting (Ryan 2011a).

While we recognise the importance of representation of reflection for students' learning about their learning or deutero-learning (Schön 1975), as well as learning to articulate and represent reflection in journals, blogs and so on, what remains conceptually and pedagogically unclear is how reflection at the time of action can assist students to learn workplace practices. The temporal distinction implicit in the term 'reflection-on-action' obviates the limitation of non-representational approaches for WIL reflection. In a recent critical examination of the epistemological issues relating to reflection, and drawing on Wittgenstein, Dohn (2011) argues that reflection is inseparable from embodied action, concluding that detached reflective activities create secondary representational practices. She argues that learning occurs in situated practice, and recommends a 'shift [in] focus from reflective activities back to the action practices themselves' (Dohn 2011, 708). Similarly, Fenwick (2009), argues that viewing knowledge and learning in this way is problematic when: 
experience is cast as static and sedimented, separated from knowledge making processes. What is foregrounded are mentalist representations or events, disembodied, static and separated from the interdependent commotion of people together in action with objects and language (Fenwick 2009, 235).

\section{Reflection-in-action}

In his seminal work The Reflective Practitioner, Schön (1983) attends to the precognitive dimensions of professional practice and so places reflection-in-action at the core of professional practice. He argues that professional practitioners tend to act based on tacit recognitions, judgment and skills, which require little reflection. Schön introduces the term 'knowing-in-action' to point to the action of making unreflective action reflective. Reflection-in-action supports in-the-moment, mindful action — or knowing what to do next - in order to deal with 'situations of uncertainty, instability, uniqueness, and value conflict' (Schön 1983, 50, cited in Yanow and Tsoukas 2009).

While Schön's work continues to be enormously influential, it has been criticised on several lines. Despite Schön's claims that he is attending to knowinginaction (1983), Eraut (1994) is critical of Schön's tendency to make reflection-inaction too rational, and suggests that Schön's (1983) choices of passive examples to illustrate reflection-in-action lack the speed and intensity of action found in many practices. Similarly, Beckett (1996) takes up this point and highlights the limitations of Schön's (1983) examples of reflection in 'hot-action', such as classroom teaching. Kotzee (2012), drawing on Searle's (1995) approach to practice, examines what he calls the missing social dimension of Schön's reflective practice. Others suggest a move away from the metaphor of reflection altogether, preferring terms such as mindfulness (Langer 1997) or diffraction (Keevers and Treleaven 2011) as being more appropriate metaphors to highlight the recalibration of action as it happens. 
In their phenomenological critique of Schön (1983), and following Dreyfus' (1991) interpretation of Heidegger, Yanow and Tsoukas (2009) attend to what they see as Schön's cognitive bias and the limitations it imposes on embodied improvisation. The authors make the distinction between feedback, a cognitive process of reflection on action, and backtalk, the resistance to materials at hand.

One can ask another for feedback; yet one does not ask one's materials to talk back-they just do, without being asked, when they resist going where the practitioner is trying to move them. In a university context, for example, one can ask students for feedback at the end of a lecture or a course, or get feedback on one's papers from colleagues or reviewers. In the midst of teaching, 'backtalk' emerges through students' eyes or the quality of silence or energy in the room, when students communicate that they are resisting the ideas that have been articulated, or do not understand them - or perhaps really do get them and find them exciting (Yanow and Tsoukas 2009, 1348)

Yanow and Tsoukas (2009) suggest that 'surprise' occurs in the moment of the practice performance, when backtalk happens unexpectedly, and that such surprise necessitates a reflective response from practitioners in-the-midst-of-action. Again following Dreyfus (1991), Yanow and Tsoukas (2009) enumerate various types and levels of surprise, including 'malfunction', 'temporary breakdown' and then 'total breakdown'. As breakdown occurs, different improvisatory responses are prompted, ranging from unintentional (spontaneous readjustments) to deliberate or thematic (specifically intentional) moves (Yanow and Tsoukas 2009, 1342). Following the critique by Yanow and Tsoukas (2009), from this point in the paper we use the term ‘in-the-midst-of-action’ to distinguish our approach from Schön’s (1983).

Despite the above critiques, in WIL, the literature remains focused on after-thefact, secondary practices of reflection that are required for assessment. We suggest that two very significant questions remain unanswered for those seeking to undertake reflection in WIL in support of student acquisition of professional practice: How is reflection in WIL represented without resorting to the development of secondary 
practices that change the focus of reflection away from learning workplace practices? How is reflection-in-the-midst-of-action dealt with pedagogically?

In an attempt to address these questions, the following section develops several theoretical strands drawing on practice theory and phenomenology to achieve greater clarity on how workplace practices are learned and developed and their relationship with reflective activities.

\section{Practice-based approaches}

The recent 'turn to practice' in social theory and philosophy positions practices as the primary form of social analysis (Schatzki et al. 2001). Drawing strongly on Wittgenstein and Heidegger, Schatzki (1996) locates practices ontologically by suggesting that social relations leading to order within society occur through the 'intelligibility' and 'sociality' acquired through shared practices. In other words, we learn how to act intelligibly through the socialisation that occurs during the performance of everyday practices. This paper adopts the view based on the work by Schatzki (1996; 2002), which holds that practices are performed and understood through shared sayings and doings oriented to achieving specific, predetermined ends. Such an approach is consistent with students in WIL undertaking work placements where they are socialised into a new learning context or 'world' as they learn the doings and sayings that enable them to undertake (the intelligible) performance of workplace practices.

\section{A 'world' of practice}

From a Heideggerian view, a 'world' can denote a social milieu in which one is proximally located (Blattner 2006). The structure of a 'world' is 'articulated in terms of all the different kinds of actions, purposes, roles and ways of organising one's life that 
are available to us' (Wrathall 2005, 22) within a particular setting. Learning these practices, along with material entities that constitute the world, is inseparable from socialisation into this world. Examples include a university, a particular industry or corporate arena. Thus WIL students enter the corporate world in their placement and, through socialisation in practices, enter the practice community by their intelligible performance of practices, such as the ability to articulate important language-based distinctions and judgments.

\section{Orders of practices: Dispersed and integrative}

Schatzki (1996) makes an important distinction between dispersed and integrative practices, which he considers (ontologically) different — but complementary — orders of practices. Dispersed practices are 'sets of doings and sayings held together by an understanding they express... and are widely dispersed among different sectors of social life' (Schatzki 1996, 91). In contrast, integrative practices are more complex, and are described by Schatzki as 'sets of doings and sayings that are linked by understandings, explicit rules (principles, precepts and instructions) and teleo-affective structuring (hierarchies of ends, tasks, projects, beliefs, emotions and/or moods)" (Schatzki 1996, 103). Further, he suggests that practices may be grouped in bundles of related practices or linked in chains of practices (Schatzki 1996; 2002).

The practice of writing a reflective journal is recognisable as an integrative practice, because it has a well-defined structure. Following the Schatzkian approach (1996; 2002), students must understand what reflection is and be able to perform reflection in doings and sayings, such as reflective writing, discussion and so on. They

must also develop competence in writing a reflective journal in accordance with specific norms or rules central to 'good' journal writing, as determined by those competent at 
the practice of writing journals. Finally, reflective journals have teleo-affective structures, because they are written for specific purposes, such as for demonstrating articulable knowledge for assessment. Therefore, students may become affectively committed to writing a good journal in order to achieve a successful grade.

\section{Reflection-in-the-midst-of-action as a dispersed practice}

In contrast to the integrative practice of writing a reflective journal, we suggest that reflection that occurs in the moment, in a workplace, is a dispersed practice - not a discrete, separate practice, but a subsidiary set of doings and sayings (such as questioning, observing, watching, listening, copying, checking) that arises in the event of perplexity, uncertainty or doubt about how to proceed in the performance of the integrated practice in progress. This type of reflection is unnecessary during uninterrupted, fluent performance of other integrative practices, but occurs when there is breakdown. Thus, in the dispersed practice of reflection-in-the-midst-of-action students' attention, or what Polyani calls 'focal awareness', is on the embodied performance of the doings and sayings that comprise the practice, while having, at the most, only a subsidiary (cognitive) awareness of the rules and norms of the practice (Yanow and Tsoukas 2009). Therefore, one could argue that in one sense, the practice is unreflective.

In our view, this dilemma is at the heart of the problem with understanding reflection as it happens. If we say reflection occurs when practice breaks down and is subsumed into specific actions denoted by questioning and observing for instance, then is the metaphor 'reflection' made redundant? In order to move beyond this ontological and methodological conundrum, we turn again to a phenomenological approach, this 
time to the integrative practice of learning skills, in which the dispersed practice of reflection-in-the-midst-of-action exists as a subsidiary.

Dreyfus and Dreyfus (2005) present a five-stage phenomenological approach of skill acquisition, in which they underline the importance of intuitive judgment in learning practices. First, at the novice stage, students have a general (though limited) understanding of the practice, but lack contextual knowledge. The instructor decomposes the task environment into features recognised by the student, and the student is given specific rules to follow. In the second stage, the advanced beginner, the student begins to develop an understanding of context - either alone or with the assistance of the instructor. Learning is still detached and analytic. The third stage, competence, occurs when the student recognises a potentially overwhelming number of elements and procedures, but a sense of what is important in a particular situation is missing. To cope, students learn (through instruction or experience) to develop a plan and restrict themselves to a small number of relevant features. Students must learn to decide what to do in each situation without being sure of success (Dreyfus and Dreyfus 2005, 784). Facing this uncertainty, coping becomes frightening, and learners feel more responsible for their choices and judgments, which may lead to confusion or failure. However, if things work out, the competent student then feels elated. Interestingly, the emphasis here is on emotional involvement; emotional detachment leading to objective operation will not lead to expertise. Rather, unless the trainee stays emotionally involved, they may withdraw and become detached and disinterested.

The fourth stage is proficiency. The detachment of the novice is replaced by involvement and commitment; that is, the "emotional commitment strengthens successful choices and inhibits unsuccessful ones' (Dreyfus and Dreyfus 2005, 786). Discrimination leads to the formulation of plans of action, and certain actions stand out 
as important in particular contexts. Action becomes less stressful and easier as the earner 'sees' what needs to be done. In the final, fifth stage, expertise, the practitioner sees what needs to be done and decides how to do it (Dreyfus and Dreyfus 2005, 787). Thus, the ability to make refined distinctions distinguishes the expert, who operates intuitively in each situational response.

By linking Dreyfus and Dreyfus' (2005) intuitive approach to skill development with Schatzki's (1996) practice structure and notion of dispersed and integrative practices, along with Yanow and Tsoukas' (2009) emphasis on the surprise of breakdown, we have the means to identify and discuss the performance of reflection-inthe-midst-of-action in a case study.

\section{Investigating reflection in-the-midst-of-action}

The setting of the study is the commerce internship at the University of Wollongong, a third-year undergraduate elective subject comprising sixteen days' placement and reflective assessments, including a journal and daily e-logs. Students write a 2,500 word reflective journal post-placement on what they learned overall in their placement experience. The e-logs support this journal and are written each day of placement, requiring students to respond to four areas:

Discuss or list the tasks or activities you engaged in today.

Discuss how you contributed to the tasks, what your role was in these tasks and what you thought about your role.

Discuss whom you came into contact with.

Overall ideas, feelings or impressions.

Our initial study aim was to look for traces of reflection-in-the-midst-of-action in forty students assessments over two semesters. We performed a content analysis of their two assessment tasks: reflective journals and e-logs. Many students clearly demonstrated the use of secondary practices, including levels of reflection, but we also noticed how 
the structured journal questions constrained demonstration of any in-the-moment development of integrated work practices, and thus reflection in-the-midst-of action. Similarly, we noticed that the e-logs as representations after the fact, couldn't capture all of the tacit, unarticulated bodily actions that occurs in-the-midst-of-action as students calibrate and attune their practices. However, being temporally closer to the action and written using a more descriptive genre the e-logs were, in fact, a more useful method for reflection in-the-midst-of-action. Through the e-logs students were able to describe the doings and sayings that were undertaken during the placement, signalling some evidence of reflection in-the-midst-of action.

\section{Illustrative case study}

In contrast to our expectations, the e-logs and journals did not take us to the heart of the reflective process occurring in action. In fact, they led us to see more clearly that the engagement with students' reflection in the moment may be better captured in their narrative re-constructions of their performance of actions. In order to explicate this further, we present a re-constructed narrative as an illustrative case study of the authors' sense-making from a single student. The case study approach has been employed extensively as a research strategy. (Yin 2003) and is consistent with phenomenology (Yanow and Schwartz-Shea 2006) and practice-based approaches (Schatzki 1996; 2002) for capturing the doings and sayings that comprise the practice world. This case study typifies the sort of experience encountered by students and highlights the restrictions of the e-log for reflection-in-the-midst-of-action. Our narrative construction serves both to make visible and demonstrate reflection-in-the-midst-of-action, and to highlight the constraints of the pedagogical structure for supporting student reflection in-the-midstof-action, and thus learning workplace practices. 
'Nina' is a third-year accounting student performing an internship at a large, not-for-profit organisation. Nina's internship is in the corporate services division, assisting accounts payable and receivable, and reviewing and preparing the quarterly budget. In days one to four, Nina is orientated to the workplace, the finance team and into basic workplace accounting practices. She is shown how to perform the accounts payable practices, comprising activities such as entering accounts, establishing new creditors/suppliers and using the organisation's new accounting software. Nina describes her concern at not knowing how things work, yet (the context) acknowledges her introduction into basic practices as the building block of accounting practices. She identifies her novice skills and tentativeness in asking others for help, saying, 'It's hard not to feel as though you are slowing their day up'. Such descriptions are typical of newcomers in a workplace, and the novice stage of expertise (Dreyfus and Dreyfus 2005), as demonstrated through her reflective awareness of her limited knowledge and understanding of context.

Initially, Nina describes her apprehension towards her supervisor's ('Valery'), upcoming work leave of absence by stating that 'fitting into the bigger picture has not clicked as yet'. Moving towards a more active role over several days, Nina continues to rely on Valery, who helps her learn more complex accounting practices. After several days, Nina begins to demonstrate actions associated with the advanced beginner stage, still relying heavily on Valery for guidance, but moving into more complex integrated accounting practices, such as calculating expenses for the year and coming up with a deficit or surplus for the allocated funding. However, it is clear from her comments that her actions (doings and sayings) are still detached from the wider organisational operations (Dreyfus and Dreyfus 2005). For example, on day 4 she comments on how 
'important that the figures be correct' and her surprise 'at the detailed required - near enough is not good enough', noticing the team pays particular attention to detail.

Midway through her internship placement, on day 7, Nina continues to grapple to understand the contextual complexity of the organisation. The focus of this day is on budgeting practices, and thus her activities are to review, make recommendations and copy and distribute the quarterly budget figures. To complete these activities she requires detailed knowledge of context, an 'understanding [of] who works in which section, which assistant manager goes with which executive manager, what programs does each executive manager control... [which] required an internal knowledge which perhaps was beyond my current understanding'. While she has not yet developed the knowledge of such complex relationships, driven by her sense of commitment to perform well she makes judgments and performs actions that cause her great concern. She summarises:

Today was a disaster, I really was not on the same page as the manager. Given that I have no history with the organisation and am still trying to understanding who does what, I found it very difficult to look at a budget for a section in a company and make suggestions on where they could improve, to meet their targets. I felt a little inadequate, I felt like I should have been able to add something, but the small contributions I did make didn't seem to be anything like what the manager wanted or there was always a story behind why each section is different eg the funding structure may be different, all legitimate, but I couldn't help but feel I was wasting the day away not being very productive at all. However, the day did remind me of how difficult it is to be a 'learner'...

Nina describes here how her lack of knowledge of context constrains her ability to perform her workplace practices. She articulates her affective commitments, feeling vulnerable, through doubts and frustrations, which make clear that getting this right is very important to her (teleo-affectivity). Here we suggest that she attempted to innovate but, due to our inability to observe her unarticulated actions we are left to speculate on the in-the-moment dispersed practices of reflection as she tries to make sense of the situation. This struggle suggests the third stage, competence (Dreyfus and Dreyfus 
2005), which involves sensing what is important and feeling the disappointment in failing to perform the task.

The following day, the manager suggests that they work through the budget together, demonstrating the norms of the integrative practice of budgeting for the quarter through telling Nina what to focus on and providing examples of recommendations to managers. Nina expresses relief and the feeling of security in this way of learning, and articulates finding solace in new understandings of how the rules and reasoning supports procedures.

On Nina's tenth day, she notes, 'Today all the data entry and background work over the past 5 weeks really started to gel together'. While attending a budget meeting with a divisional manager, Nina meshes her data-entering practices to the larger organisational accounting practices and purposes. She states, 'I could see the impacts of the preparation work in relation to the forecasts and the report production'. Nina's elogs suggest that she is becoming socialised by learning norms and rules, and is practising doings and sayings of the integrative practice of accounting. She is learning to navigate her way intelligibly in the new world of accounting practice.

\section{Practices and reflection-in-the-midst-of-action}

In the light of the case study, we now return to address the earlier questions. How is reflection in WIL represented without resorting to the development of secondary practices that change the focus of reflection away from learning workplace practices? Important implications exist in identifying WIL reflection-in-the-midst-of-action as a dispersed practice, linked to the performance of integrated workplace practices. Reflection as a subsidiary practice is ontologically inseparable from the integrated practices necessary for students to achieve workplace competence, and is therefore 
impossible to separate from the integrated practices themselves. Reflection-in-themidst-of-action (as a dispersed practice) becomes evident in a range of attuned activities, depending on the particular integrative practice performed, the context of the practice and the level of skill of the practitioner. However, the problem of how to represent this type of reflection remains intractable. We suggest if this type of reflection is to be identified so that it can be encouraged in student learning, then consideration of reflection as a dispersed practice is unhelpful, and that examining the skill development processes of learning more defined integrative practices is inevitable. However, the move must be to practices of skill development, not to representing the reflection in secondary practices temporally and spatially; in other words, by attending to skill development and how workplace practices are developed.

A way forward would be to link the theoretical strands of practice structures (Schatzki 1996) with the surprise and disruption caused by breakdown (Yanow and Tsoukas 2009), along with the skill development approach for learning practices (Dreyfus and Dreyfus 2005). This tripartite approach would help make clear how reflection-in-the-midst-of-action could be useful for developing pedagogy for WIL work placements.

\section{WIL reflection-in-the-midst-of-action pedagogical activities}

In order to facilitate improved student learning of workplace practices, we suggest a threefold approach: a pre-placement workshop, informal student discussions with workplace supervisors and evidence through assessment. These activities aim to refocus students' attention on the performance of their workplace practices, and not on other secondary, integrative practices (such as journal writing).

Prior to WIL placements, we suggest that students participate in a pre-placement 
workshop to engage students in reflection in-the-midst-of-action through unpacking three central tenets. First, students are engaged in discussion about the reflection metaphor, how the term is used and the distinction between reflection-on-action and reflection-in-the-midst-of-action. Both are shown to be useful for different areas of reflection, and examples are presented of both during the pre-placement activities. We suggest Ryan's (2011a) structured questions as a helpful framework. Second, students discuss practice development, drawing on Schatzki's (1996) distinction between dispersed and integrative practices and the importance of practice structure. Third, students examine and discuss Dreyfus and Dreyfus (2005) five-stage approach to developing expertise.

These three points may involve asking students to respond to their current university level knowledge and skills, in order to position their skill development. In turn, to facilitate this activity, students might draw up the five-stage model, locate their current level and the level they hope to move to through the internship. The facilitator then runs through how stages two and three are the most likely stages in WIL, and unpacks the various reasons.

Next, a discussion of breakdown is facilitated around key questions. What does breakdown look like? What happens? What do you do? Drawing out these questions leads into discussing backtalk. Students are encouraged to think about their own examples of backtalk and raise questions. Surprise, doubt and frustrations are linked to the notion of backtalk and the various stages of breakdown are identified. Affective commitment is important here and can be discussed by asking the students questions such as: How did you feel when this breakdown occurred? Why was it important that you sought to resolve the issue? Teleo-affective dimensions of practice underpin this discussion, highlighting that in general people seek to resolve problems that matter to 
them. Commitments to the internship process and learning discipline practices are discussed, reminding students that these commitments may vary and can be influenced by incidents of breakdown.

The second of the three components is to implement informal discussions between student and supervisor during placement. We suggest a non-assessable, developmental activity that draws on the supervisor's direct observation of the student's performance of the workplace practice. This activity is not designed to be a checklist of skills attainment, nor a compulsory university-driven assignment, but rather a learningcentric activity. To this end, a practice development discussion may be useful as an informal discussion between workplace supervisors and students. This informal conversation may take place over several stages of the internship: at the beginning, middle and end. The middle discussion is particularly important, and should be aimed at providing formative feedback around the observations of the supervisor on the student's practice, as well as a reciprocal opportunity for students to take note of their development practices. We propose four prompting questions that draw on Schatzki's definition of practices: To what extent [do you/does the student] demonstrate understandings of the workplace practice? How [do you/does the student] perform practice norms and rules of the organisation? Comment on [your/the student's] feelings towards [your/their] commitment to the practice and placement. In which ways can I improve my workplace practice? Positioning these questions against Dreyfus and Dreyfus' (2005) stages of development may also be useful to help the intern map progress, through stages one, two and three.

The third component is to provide evidence through assessment. As well as satisfying subject requirements, assessments are useful as they offer students different subject or course related intensions for completing them. For this reason, we feel the 
balance between non-assessable informal discussions and assessment driven activities is worthwhile. As identified in the case study, assessment maybe in the form of e-logs, which are beneficial for recording learning and practice development over time. It is important however the assessments selected be tailored to the WIL program and course (Dean, Sykes, Agostinho and Clements, 2012).

\section{Conclusions}

By adopting a practice approach to reflection, this paper takes up Boud's (2010) call for researchers to pursue research trajectories that consider different ways of thinking about reflection that consider 'the complexities and relational qualities of practice' (Boud 2010, 36). Reconceptualising student reflective activities as reflective practices supports student reflection-in-the-midst-of-action through emphasising learning where knowing is performed in practice. In WIL, reflective activities that only focus on reflection-onaction are limited by presupposing student experience 'as static and sedimented, separated from knowledge making processes' (Fenwick 2009, 235). When learning activities are only concerned with reflections on events after they have occurred, the knowledge and representations of such knowledge are 'separated from the interdependent commotion of people together in action with objects and language' (Fenwick 2009, 235). This separateness of real-world practices and classroom learning is contrary to the very aim of WIL, which is to provide a bridge between higher education and the workplace. Therefore, it is important for designers of WIL curricula to connect learning activities to student learning workplace practices.

Learning in WIL workplaces is of an order different from that acquired by students in a classroom context. We do not wish to diminish the importance of learning in the classroom context, but to support students' learning and knowledge in ways that 
are commensurate with the workplace context. Moves to consider reflection as a practice and the focus of reflection to reflection-in-the-midst-of-action, both support a learning approach that is more congruent with workplace action and context (Boud 2008). Re-conceptualising reflection as a practice and drawing on phenomenology supports and builds on Schön's temporal distinction. Finally, the paper provides an important move towards Dohn's recommendations for reflection to adopt epistemological positioning aligned with situated learning in which 'the primary ontology of knowledge and competence is situated realisation in the very doing itself' (Dohn 2011, 707). 


\section{References}

Bain, J.D., R. Ballantyne, C. Mills and N.C. Lester. 2002. Reflecting on practice: Student teachers' perspectives. Flaxton, Qld: Post Pressed.

Beckett, D. 1996. Critical judgement and professional practice. Educational Theory 46(2): 135-149.

Beckett, D. and P. Hager. 2002. Life, Work and Learning: Practice in postmodernity. London and New York: Routledge.

Blattner, W. 2006. Heidegger's Being and Time. New York: Continuum International Publishing Group.

Boud, D. 1999. Avoiding the traps: Seeking good practice in the use of self assessment and reflection in professional courses. Social Work Education: The International Journal 18(2): 121-132.

Boud, D. 2001. Using journal writing to enhance reflective practice. New Directions for Adult and Continuing Education 90(2): 9-17.

Boud, D. 2008. How can practice reshape assessment? In Assessment, Learning and Judgment in Higher Education, ed. G. Joughin. London, Springer.

Boud, D. 2010. Relocating reflection in the context of practice. In Beyond Reflective Practice: New approaches to professional lifelong learning, ed. H. Bradbury, N. Frost, S. Kilminster, M. Zukas. London and New York: Routledge, pp. 25-36.

Boud, D., R. Keogh and D. Walker, eds. 1985. Reflection: Turning experience into Learning. London: Kogan Page.

Dean, B.A., Sykes, C., Agostinho, S., and Clements, M. 2012. Reflective assessment in work-integrated learning: To structure or not to structure, that was our question. Asia Pacific Journal of Cooperative Education 13(2): 103-113. 
Dewey, J. 1910. How we think. Boston, New York, Chicago: D. C. Heath \& Co Publishers.

Doel, S. 2009. Fostering student reflection during engineering internships. Asia-Pacific Journal of Cooperative Education 10(3): 163-177.

Dohn, N.B. 2011. On the epistemological presuppositions of reflective activities. Educational Theory 61(6): 671-708.

Dreyfus, H. 1991. Being-in-the-World: A Commentary on Heidegger's Being and Time, Division 1. New Baskerville: MIT Press.

Dreyfus, H.L. and S.E. Dreyfus. 2005. Expertise in real world contexts. Organization Studies 26(5): 779-792.

Dyment, J. E., O'Connell, T. S., and Boyle I. 2011. The intersection of Web 2.0 technologies and reflective journals: An investigation of possibilities, potential and pitfalls. Journal of Outdoor Recreation, Education and Leadership. 3(3): $137-150$

Eraut, M. 1994. Developing Professional Knowledge and Competence. London: The Falmer Press.

Fenwick, T. 2009. Making to measure? Reconsidering assessment in professional continuing education. Studies in Continuing Education 31(3): 229-244.

Francis, H. and J. Cowan. 2008. Fostering an action-reflection dynamic amongst student practitioners. Journal of European Industrial Training 32(5): 336-346.

Freeman, R. and K. Le Rossignol. 2010. Taking risks — experiential learning and the writing student. Australian Journal of Adult Learning 50(1): 75-99.

Gibson, M., P. Hauf, B. S. Long and G. Sampson. 2011. Reflective practice in service learning: possibilities and limitations. Education and Training 53(4): 284-296. 
Grossman, R. 2009. Structures for facilitating student reflection. College Teaching 57(1): 15-22.

Hackett, S. 2001. Educating for competency and reflective practice: Fostering a conjoint approach in education and training. Journal of Workplace Learning 13(3): 103112.

Heel, D., Sparrow, J. and R. Ashford. 2006. Workplace interactions that facilitate or impede reflective practice. Journal of Health Management 8(1): 1-10.

Howard, P. 2009. Articulating the learning: professional practice made explicit. AsiaPacific Journal of Cooperative Education 10(3): 177-188.

Keevers L. and L. Treleaven. 2011. Organizing practices of reflection: A practice-based study. Management Learning 42(5): 505-20.

Kember, D., Jones, A., Loke, A., McKay, J., Sinclair, K., Tse, H., Webb, C., Wong, F., Wong, M., and E. Yeung.1999. Determining the level of reflective thinking from students' written journal using a coding scheme based on the work of Mezirow. International Journal of Lifelong Education 18(1): 18-30.

Knight, B. 1996. Reflecting on reflective practice. Studies in the Education of Adults 28(2): 162-184.

Kotzee, B 2012. Private practice: Exploring the missing social dimension in 'reflective practice'. Studies in Continuing Education. 34(10: 5-16.

Langer, E. 1953. Feeling and Form. New York: Charles Scribner's Sons.

Langer, E. 1997. The Power of Mindful Learning. Cambridge MA: Da Capo Press.

Mezirow, J. 1991. Transformative Dimensions of Adult Learning. San Francisco: Jossey-Bass.

Patrick, C.-J., D. Peach, C. Pocknee, F. Webb, M. Fletcher and G. Pretto. 2008. The WIL [Work Integrated Learning] report: A national scoping study. Australian 
Learning and Teaching Council (ALTC) Brisbane: Queensland University of Technology.

Raelin, J. 2007a. Toward an epistemology of practice. Academy of Management Learning and Education 6(4): 495-519.

Raelin, J. 2007b. The return to practice in Higher Education: resolution of a paradox. Journal of General Education 56(1): 57-77.

Ryan, M. 2011a. Conceptualising and teaching discursive and performative reflection in higher education. Studies in Continuing Education iFirst: 1-17.

Ryan, M. 2011b. Improving reflective writing: a semiotic perspective. Teaching in Higher Education 16(1): 99-111.

Schatzki, T. 1996. Social Practices. A Wittgensteinian Approach to Human Activity and the Social. Cambridge: Cambridge University Press.

Schatzki, T., Knorr-Cetina, K. And E.V Savigny, eds. 2001. The practice turn in contemporary theory. New York: Routledge.

Schatzki, T.R. 2002. The Site of the Social: A philosophical account of the constitution of social life and change. University Park: Pennsylvania State University Press.

Schön, D.A. 1975. Deutero-learning in organizations: Learning for increased effectiveness. Organizational Dynamics. 4(1): 2-16.

Schön, D.A. 1983. The Reflective Practitioner. San Francisco: Jossey-Bass.

Schön, .A. 1987. Educating the Reflective Practitioner. Jossey-Bass Publishers: San Francisco.

Searle, J. 1995. The Construction of Social Reality. London: Continuum.

Sen, B.A. 2010. Reflective writing: A management skill. Library Management 31(1/2): 79-93. 
Wrathall, M. 2005. How to Read Heidegger. New York \& London: W.W. Norton \& Company.

Yanow D. and H. Tsoukas. 2009. What is reflection-in-action? A phenomenological account. Journal of Management Studies 46(8): 1339-134.

Yanow, D. and P. Schwartz-Shea, eds. 2006. Interpretation and Method: empirical research methods and the interpretive turn. London: M.E. Sharpe.

Yin, R. 2003. Case Study Research. Thousand Oaks California: Sage. 